\title{
Characterization of Neisseria gonorrhoeae isolates detected in Switzerland (1998-2012): emergence of multidrug-resistant clones less susceptible to cephalosporins
}

\author{
Andrea Endimiani ${ }^{*}$, Yuvia N Guilarte ${ }^{1}$, Regula Tinguely ${ }^{1}$, Lea Hirzberger ${ }^{1,2}$, Sylvia Selvini ${ }^{1}$, Agnese Lupo ${ }^{1}$, \\ Christoph Hauser $^{2}$ and Hansjakob Furrer ${ }^{2}$
}

\begin{abstract}
Background: The spread of Neisseria gonorrhoeae $(\mathrm{Ng})$ isolates resistant to the clinically implemented antibiotics is challenging the efficacy of treatments. Unfortunately, phenotypic and molecular data regarding $\mathrm{Ng}$ detected in Switzerland are scarce.

Methods: We compared the characteristics of Ng detected during 1998-2001 $(n=26)$ to those detected during 2009-2012 ( $n=34$ ). MICs were obtained with the Etest and interpreted as non-susceptible (non-S) according to EUCAST criteria. Sequence type (ST) was achieved implementing the NG-MAST. BlaTEM, ponA, penA, mtrR, penB, tet (M), gyrA, parC, mefA, ermA/B/C/F, rp/D, rp/V, and 23S rRNA genes were analyzed.

Results: The following susceptibility results were obtained (period: \% of non-S, MIC $_{90}$ in mg/L): penicillin (1998-2001: 42.3\%, 3; 2009-2012: 85.3\%, 16), cefixime (1998-2001: 0\%, $\leq 0.016$; 2009-2012: 8.8\%, 0.125), ceftriaxone (1998-2001: 0\%, $0.004 ;$ 2009-2012: 0\%, 0.047), ciprofloxacin (1998-2001: 7.7\%, 0.006; 2009-2012: 73.5\%, 232), azithromycin (1998-2001: $11.5 \%, 0.25 ;$ 2009-2012: 23.6\%, 0.38), tetracycline (1998-2001: 65.4\%, 12; 2009-2012: 88.2\%, 24), spectinomycin (1998-2001: $0 \%, 12 ; 2009-2012: 0 \%, 8$ ). The prevalence of multidrug-resistant (MDR) isolates increased from $7.7 \%$ in 1998-2001 to 70.6\% in 2009-2012. International STs and genogroups (G) emerged during 2009-2012 (G1407, 29.4\%; G2992, 11.7\%; G225, 8.8\%). These isolates possessed distinctive mechanisms of resistance (e.g., G1407: PBP1 with L421, PBP2 pattern XXXIV, GyrA with S91F and D95G, ParC with S87R, PorB with G120K and A121N, mtrR promoter with A deletion).

Conclusions: The prevalence of penicillin- ciprofloxacin- and tetracycline-resistant $\mathrm{Ng}$ has reached dramatic levels, whereas cefixime and ceftriaxone show MICs that tend to increase during time. International MDR clones less susceptible to cephalosporins are rapidly emerging indicating that the era of untreatable gonococcal infections is close.
\end{abstract}

Keywords: Gonococcus, ST1407, MIC, Ceftriaxone, Cefixime, MDR, NG-MAST, PBP1, PBP2, Mosaic

\section{Background}

Neisseria gonorrhoeae $(\mathrm{Ng})$ is the etiologic agent of the second most common sexually transmitted infection (STI) globally [1]. The number of gonococcal infections is rapidly increasing, especially because subjects are often asymptomatic. This condition contributes to the spread of the pathogen, but also to the silent progression of the infection to more serious clinical conditions as

\footnotetext{
* Correspondence: aendimiani@gmail.com

'Institute for Infectious Diseases, University of Bern, Bern, Switzerland

Full list of author information is available at the end of the article
}

the pelvic inflammatory diseases. Therefore, along with the implementation of effective preventive strategies, the administration of adequate antibiotic treatments can contribute to the control of infections $[2,3]$.

Unfortunately, $\mathrm{Ng}$ has a remarkable ability to develop resistance to all of the clinically implemented antibiotics [4]. In brief, resistance to ciprofloxacin (CIP) is usually due to amino acid substitutions in GyrA and ParC $[5,6]$. Azithromycin (AZT) can become inactive due to mutations in the four copies of the 23S rRNA, production of methylase enzymes encoded by acquired genes (e.g.,

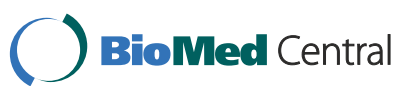


ermB/F), or substitutions in the L4 and L22 ribosomal proteins [5,7]. Tetracycline (TET) is usually ineffective because of tet $(\mathrm{M})$ gene acquisition [3,5]. Resistance to penicillin (PEN) is due to production of acquired TEM1 -like $\beta$-lactamases or alterations of the penicillin binding proteins (PBPs; e.g., amino acid substitutions for PBP1 and PBP2) $[3,4,8]$. Notably, the over-expression of the MtrCDE efflux pump due to substitutions in its repressor MtrR or deletions/insertions in the mtr promoter region may reduce susceptibility to all of the above mentioned drugs [5,9], whereas substitutions in the PorB outer membrane porin may affect PEN and TET [10].

However, the most threatening global concern is represented by the recent emergence of $\mathrm{Ng}$ isolates resistant to cefixime (CFX) and, even more importantly, to ceftriaxone (CRO) [11-15]. Reduced susceptibility to these cephalosporins can be due to a mixture of the mechanisms involved in penicillin resistance, but full resistance necessitates specific mosaic structures of the PBP2 that are caused by recombination events occurring between gonococcus and other commensal Neisseria species $[4,16,17]$.

Taking into account these clinical problems, and based on national and international guidelines [2,18], many countries have recently established active surveillance programs to monitor the evolution of antimicrobial susceptibility for $N g$ isolates [3,19-22], and the spread of international clones (e.g., sequence types ST1407, ST2992, and ST225) that are usually more resistant $[8,13,19,23,24]$. Clinical treatment and public health strategies for controlling gonococcal STI clearly benefit from the combined availability of these data [2,3]. However, we should note that there is a need of this compulsory information for our country. Thus, in the present work, we investigated the phenotypic and molecular characteristics of $\mathrm{Ng}$ isolates detected in Switzerland during a 15-year period.

\section{Methods}

\section{Clinical isolates}

We analyzed the $\mathrm{Ng}$ isolates collected by the Laboratory of Clinical Microbiology of the University of Bern (Switzerland) during a 15-year period and isolated implementing standard microbiological methodologies [25]. The characteristics of isolates detected during 1998-2001 ( $\mathrm{n}=26)$ were compared to those of gonococci detected during 2009-2012 ( $n=34)$. Strains had been stored at $-80^{\circ} \mathrm{C}$ over the time in glycerol stock tubes (Almedica AG). For the present study, isolates were plated on GC agar (bioMérieux) and species identification was confirmed by using the MALDI-TOF MS (Bruker Daltonik).

\section{Antimicrobial susceptibility tests (ASTs)}

Minimum inhibitory concentrations (MICs) for PEN, CFX, CRO, CIP, AZT, TET, spectinomycin (SPE) and gentamicin $(\mathrm{GEN})$ were obtained using the Etest method on GC agar plates. Results were categorized according to the 2013 European Committee on Antimicrobial Susceptibility Testing (EUCAST) criteria [26]. Production of $\beta$-lactamases was evaluated by implementing the cefinase disk (Oxoid) and also mixing $5 \mu \mathrm{L}$ of $\beta$ lactamase(s) extract with $50 \mu \mathrm{L}$ of nitrocefin $[100 \mu \mathrm{M}]$ for 1 hour. N. gonorrhoeae ATCC 49226 and Staphylococcus aureus ATCC 29213 were used as controls.

\section{Analysis of clonality}

Sequence type (ST) designation was achieved by analyzing both por and $t b p B$ genes according to the Neisseria gonorrhoeae Multi-Antigen Sequence Typing methodology (NG-MAST; http://www.ng-mast.net/) [27]. STs were clustered in genogroups (e.g., G1407, G2992, and G225) whenever possible, as previously done [23].

\section{Molecular characterization of drug resistance genes}

Genomic extraction was performed using the QIAmp DNA mini kit (QIAGEN). The following antibiotic resistance genes (and their encoded proteins) were analyzed as previously described [5]: ponA (PBP1), penA (PBP2), bla TEM $_{\text {( }}$-lactamases), gyrA and parC (quinolone resistance determining region), pen $B$ (PorB porin), $m t r R$ and $m$ trR promoter (MtrCDE efflux pump), rplD and $r p l V$ (ribosomal protein L4 and L22, respectively), the four 23S rRNA gene copies, mefA (efflux-mediated resistance mechanism), erm $A / B / C / F$ (methylase enzymes), and tet $(\mathrm{M})$ (ribosomal protection protein). DNA sequencing was performed in service by Eurofins (Ebersberg, Germany) and chromatogram traces were analyzed using DNAStar (Lasergene). Results for all of the above genes were analyzed by searching for homologies with BLAST (http://blast.ncbi.nlm.nih.gov/Blast.cgi) or by comparison with the following deposited wild-type alleles: ponA, pen $B, m t r R$ and $m t r R$ promoter, gyr $A$, parC, rplD, and rplV (GenBank: AE004969); penA (GenBank: M32091); bla $a_{\mathrm{TEM}-1}$ (GenBank: AJPQ01000032); and 23S rRNA (GenBank: CP001050).

\section{Results}

\section{Clinical isolates}

$\mathrm{Ng}$ isolates collected during 1998-2001 were from 18 males (median age 26.5; range $0-37$ years) and 8 females (median age 26.0; range 16-40 years), whereas those collected during 2009-2012 were from 30 males (median age 33.0; range 21-56 years) and 4 females (median age 25.0; range 23-49 years). In 1998-2001, samples from males were urethral $(n=17)$ and ocular swabs $(n=1)$, whereas those from females were cervical $(n=4)$, vaginal $(n=2)$, 
and wound swabs $(\mathrm{n}=1)$, or sterile fluids $(\mathrm{n}=1)$. With regard to 2009-2012, samples from males were urethral $(\mathrm{n}=$ 29) and pharyngeal swabs $(n=1)$, whereas those from females were vaginal $(n=3)$ and abscess swabs $(n=1)$.

\section{Antimicrobial susceptibility}

The MIC distributions for the eight antibiotics tested against $\mathrm{Ng}$ isolates detected during the two different periods are shown in Figure 1.

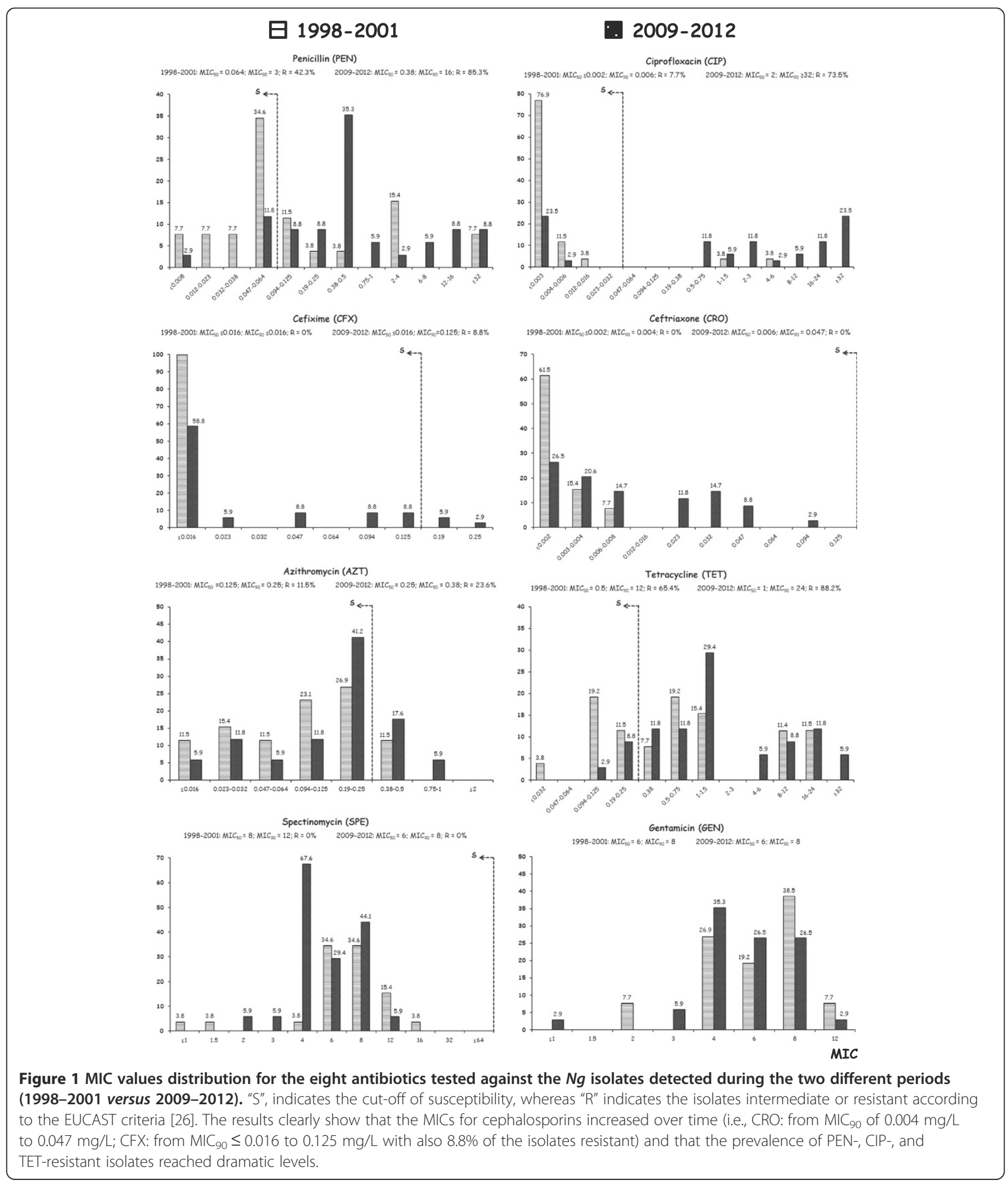


During the 15 years, gonococcal isolates showed a remarkable increase in resistance to PEN (from $42.3 \%$ to 85.3\%) and CIP (from 7.7\% to 73.5\%), but also a marked rise in resistance to AZT (from $11.5 \%$ to $23.6 \%$ ) and TET (from $65.4 \%$ to $88.2 \%$ ). With regard to cephalosporins, we noted a rise in the MIC values for both CFX (from $\mathrm{MIC}_{90} \leq 0.016 \mathrm{mg} / \mathrm{L}$ to $\mathrm{MIC}_{90}$ of $0.125 \mathrm{mg} / \mathrm{L}$, with $8.8 \%$ of resistant isolates) and $\mathrm{CRO}$ (from $\mathrm{MIC}_{90}$ of $0.004 \mathrm{mg} / \mathrm{L}$ to $\mathrm{MIC}_{90}$ of $0.047 \mathrm{mg} / \mathrm{L}$ ). Only SPE (all 60 isolates were susceptible) and GEN did not show increased MICs (Figure 1).

As shown in Table 1, the prevalence of multidrugresistant (MDR) isolates (i.e., those resistant to $\geq 3$ antibiotic classes [4]) increased from $7.7 \%$ in $1998-2001$ to $70.6 \%$ in $2009-2012$. We also noted that the isolates simultaneously resistant to four antibiotics augmented from $3.8 \%$ in $1998-2001$ to $26.5 \%$ in $2009-2012$, whereas those resistant to five antimicrobials (PEN, CIP, AZT, TET, and CFX) reached 5.9\% in 2009-2012.

\section{Clonality}

Sequencing types (STs) of $\mathrm{Ng}$ isolates detected during 1998-2001 and 2009-2012 are summarized in Figure 2.

\section{Table 1 Patterns of antimicrobial and associated resistances of the $N$. gonorrhoeae isolates detected in Switzerland during the study period ${ }^{\mathrm{a}}$}

\begin{tabular}{lcc}
\hline Antibiotics $^{\mathbf{b}}$ & No. and (\%) of isolates \\
\cline { 2 - 3 } & $\begin{array}{c}\mathbf{1 9 9 8 - 2 0 0 1} \\
(\mathbf{n}=\mathbf{2 6})\end{array}$ & $\begin{array}{c}\mathbf{2 0 0 9 - 2 0 1 2} \\
\mathbf{( n = 3 4 )}\end{array}$ \\
\hline Resistant to $\geq 2$ antibiotics: & $14(53.8)$ & $31(91.2)$ \\
-PEN and CIP & $2(7.7)$ & $25(73.5)$ \\
-PEN and AZT & $3(11.5)$ & $8(23.5)$ \\
-PEN and TET & $14(53.8)$ & $28(82.4)$ \\
-CIP and TET & $2(7.7)$ & $23(67.6)$ \\
-CIP and AZT & $1(3.8)$ & $7(20.6)$ \\
-AZT and TET & $3(11.5)$ & $8(23.5)$ \\
Resistant to $\geq 3$ antibiotics (i.e., MDR isolates): & $2(7.7)$ & $24(70.6)$ \\
-PEN, CIP, and AZT & $1(3.8)$ & $7(20.6)$ \\
-PEN, CIP, and TET & $2(7.7)$ & $23(67.6)$ \\
-PEN, AZT, and TET & $3(11.5)$ & $8(23.5)$ \\
-CIP, AZT, and TET & $1(3.8)$ & $7(20.6)$ \\
Resistant to $\geq 4$ antibiotics: & $1(3.8)$ & $9(26.5)$ \\
-PEN, CIP, AZT, and TET & $1(3.8)$ & $7(20.6)$ \\
-PEN, CIP, TET, and CFX & $0(0.0)$ & $2(5.9)$ \\
Resistant to 5 antibiotics (PEN, CIP, AZT, TET, & $0(0.0)$ & $2(5.9)$ \\
and CFX) & & \\
\hline
\end{tabular}

Note. PEN, penicillin; CIP, ciprofloxacin; AZT, azithromycin; TET, tetracycline; CFX, cefixime.

${ }^{a}$ All isolates were susceptible to ceftriaxone (CRO) and spectinomycin (SPE). " "Resistant" includes intermediate and resistant according to the EUCAST criteria [26].
In 1998-2001, only the international genogroup G25 was identified (one ST25 in 1998 and one ST3369 in 2001). In contrast, during 2009-2012 the international lineages G1407 (29.4\%), G2992 (11.7\%), and G225 (8.8\%) were detected. Most of these hyperepidemic genogroups were MDR (e.g., 9/10 of the isolates of G1407 were resistant to $\geq 3$ antibiotics). Moreover, $\mathrm{Ng}$ of G1407 possessed the highest MICs for CFX and CRO, with $\mathrm{MIC}_{50 / 90}$ of $0.125 / 0.19 \mathrm{mg} / \mathrm{L}$ and $\mathrm{MIC}_{50 / 90}$ of $0.032 / 0.047 \mathrm{mg} / \mathrm{L}$, respectively (data not fully shown; see also Table 2).

\section{Drug resistance genes}

The specific phenotypic and molecular characteristics of $N g$ detected during 2010-2012 $(\mathrm{n}=26)$ are presented in Table 2 .

Isolates with reduced susceptibility to antibiotics possessed the following specific antibiotic resistance traits: PBP1 (substitution L421P), PBP2 (mosaics II, V, XII, XIX, or XXXIV), TEM-1-like $\beta$-lactamases, GyrA (substitutions S91F, D95G, and D95A), ParC (substitutions S87R and E91G), PorB (substitutions G120K and A121D/N/G), MtrR (substitutions A39T, R44H, G45D, L47P), mtrR promoter (A deletion), and the Tet(M) protective protein. RplD, rplV and $23 \mathrm{~S}$ rRNA genes did not present mutations and erm or $m e f A$ genes were not detected.

Notably, $\mathrm{Ng}$ isolates belonging to G1407, G2992, and G225 constantly possessed specific and conserved antibiotic resistance patterns (e.g., all G1407 had PBP1 with L421P, PBP2 pattern XXXIV, GyrA with S91F and D95G, ParC with S87R, PorB with G120K and A121N, and the A deletion in the $m$ trR promoter region).

\section{Discussion}

Programs monitoring the antibiotic susceptibility of $\mathrm{Ng}$ are essential to implement adequate empirical treatments $[1,3,18,20]$. Information about the underlying molecular mechanisms of resistance is equally important to design and evaluate new rapid diagnostic systems [30]. Moreover, the incidence of $\mathrm{Ng}$ hyperepidemic clones should be carefully monitored because these isolates have the potential to spread quickly and are showing increasing resistance to most of the clinically used antibiotics $[13,19,23]$.

In 2008, Le Lin et al. described the emergence (2002) of $\mathrm{Ng}$ resistant to CIP in Geneva [31]. Very recently, Kovari et $a l$. have analyzed the susceptibility to four antibiotics (CFX, CRO, CIP and PEN) of 320 isolates collected in 1990 and from 2000 to 2012 at the University of Zurich [32]. However, up to now surveys studying the molecular characteristics, especially the clonality, of $\mathrm{Ng}$ detected in Switzerland have not yet been performed. Therefore, the aim of the present work was to fill up the lack of contemporary data regarding gonococcus implementing the methodologies suggested by the acknowledged international institutions $[19,20]$. 


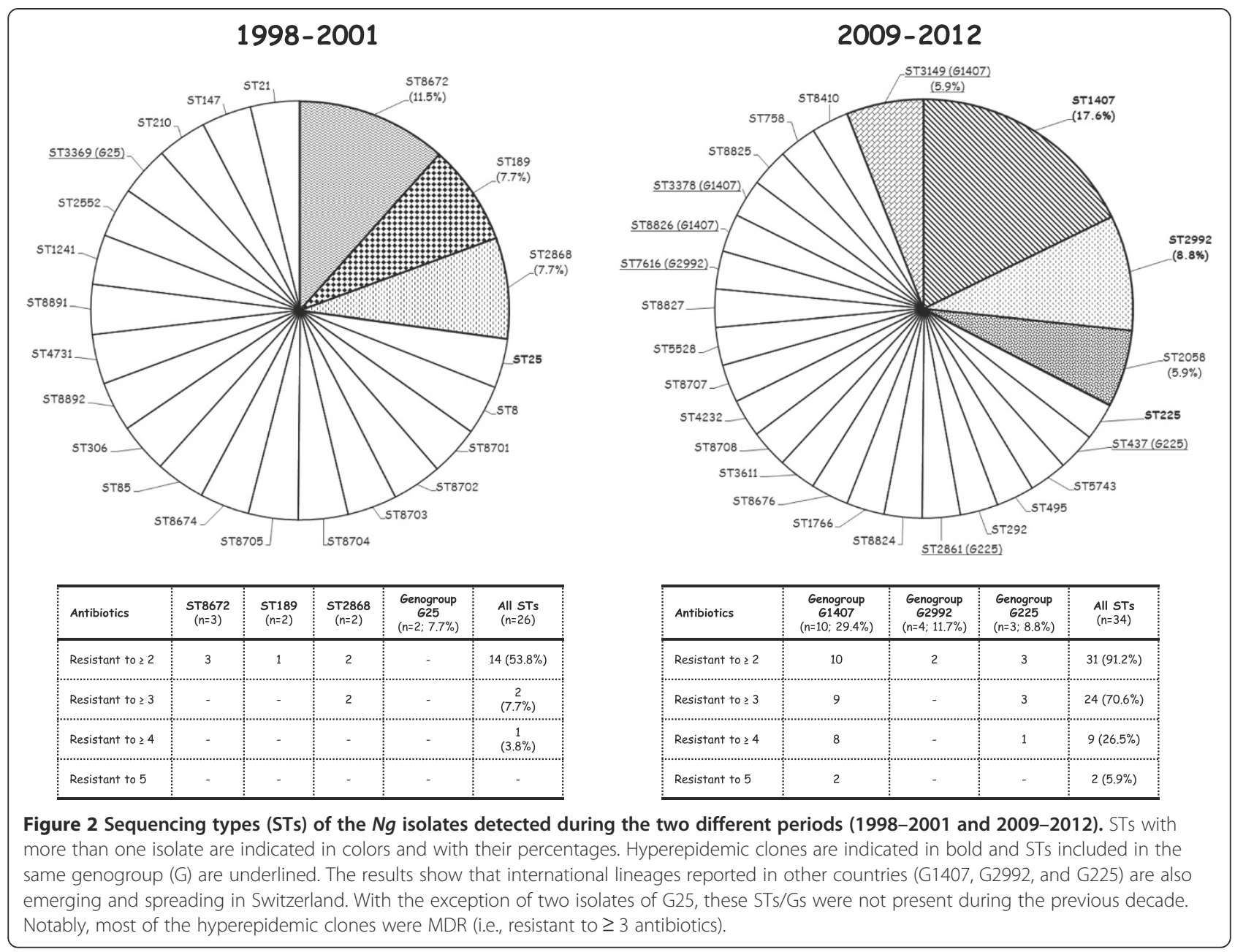

\section{Trend of antibiotic susceptibility}

Consistently with the study of Kovari et al. [32], our phenotypic data indicate that the prevalence of $\mathrm{Ng}$ resistant to either PEN or CIP increased considerably during the last decade $(>73 \%)$. However, in our study we have also observed that the occurrence of isolates simultaneously resistant to PEN, CIP, and TET has reached a dramatic level (68\%). These figures clearly show that the use of these three antibiotics for the empirical treatment of gonococcal infections is no longer safe. This phenomenon is not new and has been observed in other countries. The extensive use of antibiotic treatments without performing the ASTs has generated not only an escalation of "treatment failures" [33-36], but also a positive selective pressure for specific international MDR clones (e.g., G1407 and G225) [3,4].

Fortunately, current $\mathrm{Ng}$ isolates spreading in Switzerland seem to remain susceptible to the standard therapeutic option CRO [32,37]. However, its MICs are increasing over time ("MIC creep") as observed worldwide [3,4,20], and one should be aware that CRO-resistant isolates can emerge and spread $[4,7,11,12,14,17]$. This possible development could also be favored by the observed decreased susceptibility to AZT, an antibiotic used together with CRO to cover Chlamydia trachomatis co-infections and more recently also implemented to prevent treatment failures of gonococcal infections [33,37]. In this overall scenario, we noted that all $\mathrm{Ng}$ tested were susceptible to SPE, probably because the use of this antibiotic has been abandoned after observing outbreaks of resistant isolates in the 1980s [3,4]. SPE-resistant $\mathrm{Ng}$ are now rarely reported $[20,21]$, and this antibiotic could be reconsidered - along with gentamicin - for the treatment of infections due to MDR isolates showing coassociated reduced susceptibility to CRO and AZT [4].

\section{Emergence of successful international STs and genogroups}

The NG-MAST analysis pointed out that in the last few years the G1407, G2992, and G225 international genogroups have also reached Switzerland, now representing $\sim 50 \%$ of the overall isolates. Most likely, these lineages were initially imported by infected people who had sexual intercourse abroad, but it is difficult to 
Table 2 Phenotypic and molecular characteristics (clonality and drug resistance genes) of 26 N. gonorrhoeae isolates detected during the period $2010-2012$ in Switzerland

\begin{tabular}{|c|c|c|c|c|c|c|c|c|c|c|c|c|c|c|c|c|c|c|c|c|c|c|c|c|}
\hline \multirow[t]{2}{*}{ Isolate } & \multirow[t]{2}{*}{ Year } & \multirow{2}{*}{$\begin{array}{c}\text { ST } \\
\text { (Genogroup) }\end{array}$} & \multirow[t]{2}{*}{$\mathrm{PP}^{\mathrm{a}}$} & \multicolumn{8}{|c|}{ Minimum inhibitory concentration, $\mathrm{mg} / \mathrm{L}^{\mathrm{b}}$} & \multirow{2}{*}{$\begin{array}{c}\text { PBP1 } \\
\text { (ponA) }\end{array}$} & \multirow[t]{2}{*}{ PBP2 (penA) } & \multirow[t]{2}{*}{ TEM } & \multirow[t]{2}{*}{ GyrA } & \multirow[t]{2}{*}{ ParC } & \multirow{2}{*}{$\begin{array}{l}\text { PorB } \\
\text { (penB) }\end{array}$} & \multirow[t]{2}{*}{ MtrR } & \multirow{2}{*}{$\begin{array}{c}m t r R \\
\text { promoter }\end{array}$} & \multirow{2}{*}{$\begin{array}{c}\mathrm{L} 4 \\
(r p / D)\end{array}$} & \multirow{2}{*}{$\begin{array}{l}\mathrm{L} 22 \\
(r p / V)\end{array}$} & \multirow{2}{*}{$\begin{array}{l}235 \text { rRNA } \\
\text { (4 copies) }\end{array}$} & \multirow{2}{*}{$\begin{array}{c}\operatorname{ermA} A / \\
B / C / F \\
\text { and } \\
\text { mef } A\end{array}$} & \multirow{2}{*}{$\begin{array}{l}t e t \\
\text { (M) }\end{array}$} \\
\hline & & & & $\overline{\mathrm{PEN}}$ & CFX & CRO & CIP & AZT & TET & SPE & $\overline{\text { GEN }}$ & & & & & & & & & & & & & \\
\hline 1820606 & 2010 & 495 & + & 6 & $\leq 0.016$ & 0.006 & 0.006 & 0.38 & 96 & 12 & 8 & L421P & $X \|$ & TEM-1 & WT & WT & $\begin{array}{l}\text { G120K, } \\
\text { A121D }\end{array}$ & $\begin{array}{l}\text { A39T, } \\
\text { L47P }\end{array}$ & WT & WT & WT & All WT & - & + \\
\hline 1865296 & 2010 & 292 & & 0.25 & $\leq 0.016$ & 0.006 & 2 & 0.25 & 0.5 & 6 & 4 & L421P & $\mathrm{v}$ & & S91F, D95G & S87R & A121S & WT & $\begin{array}{c}\mathrm{A} \\
\text { deletion }\end{array}$ & WT & WT & All WT & & - \\
\hline 1872778 & 2010 & 2861 (G225) & - & 0.38 & 0.047 & 0.032 & $>32$ & 0.25 & 0.75 & 4 & 4 & L421P & $X \|$ & - & S91F, D95G & S87R & $\begin{array}{l}\text { G120K, } \\
\text { A121D }\end{array}$ & WT & $\begin{array}{c}\mathrm{A} \\
\text { deletion }\end{array}$ & WT & WT & All WT & - & - \\
\hline 1832086 & 2010 & 1407 (G1407) & - & 0.5 & 0.19 & 0.047 & 6 & 0.25 & 1.5 & 8 & 6 & L421P & XXXIV & - & S91F, D95G & $S 87 R$ & $\begin{array}{l}\text { G120K, } \\
\text { A121N }\end{array}$ & WT & $\begin{array}{c}\mathrm{A} \\
\text { deletion }\end{array}$ & WT & WT & All WT & - & - \\
\hline 1859198 & 2010 & 225 (G225) & & 0.5 & 0.047 & 0.032 & $>32$ & 0.38 & 1.5 & 8 & 8 & L421P & $X \|$ & & S91F, D95G & S87R & $\begin{array}{l}\text { G120K, } \\
\text { A121D }\end{array}$ & WT & $\begin{array}{c}\text { A } \\
\text { deletion }\end{array}$ & WT & WT & All WT & & - \\
\hline 1910312 & 2010 & 2992 (G2992) & & 0.094 & $\leq 0.016$ & 0.003 & $\leq 0.002$ & 0.25 & 0.38 & 6 & 4 & WT & $\|$ & & WT & WT & WT & $\begin{array}{l}\text { A39T, } \\
\text { R44H }\end{array}$ & WT & $W T^{d}$ & WT & All WT & & \\
\hline 1869994 & 2010 & 1766 & + & 6 & $\leq 0.016$ & 0.006 & 0.75 & $\leq 0.016$ & 6 & 6 & 4 & L421P & $\| g$ & TEM-1 & S91F, D95A & $\mathrm{S} 87 \mathrm{~N}$ & G120D & WT & $\begin{array}{c}\mathrm{A} \\
\text { deletion }\end{array}$ & WT & WT & All WT & & + \\
\hline 1912168 & 2010 & 8676 & + & 32 & $\leq 0.016$ & $\leq 0.002$ & 3 & 0.032 & 8 & 4 & 4 & L421P & $\|$ & TEM-1 & S91F, D95G & $S 87 R$ & $\begin{array}{l}\text { G120K, } \\
\text { A121D }\end{array}$ & WT & WT & WT & WT & All WT & - & + \\
\hline 1922603 & 2011 & 3149 (G1407) & - & 0.38 & 0.19 & 0.047 & 16 & 0.25 & 1.5 & 8 & 6 & L421P & XXXIV & - & S91F, D95G & $\mathrm{S} 87 \mathrm{R}$ & $\begin{array}{l}\text { G120K, } \\
\text { A121N }\end{array}$ & WT & $\begin{array}{c}\text { A } \\
\text { deletion }\end{array}$ & WT & WT & All WT & - & - \\
\hline 1996003 & 2011 & 3611 & + & 12 & $\leq 0.016$ & 0.008 & $>32$ & 0.125 & 96 & 8 & 4 & L421P & $X I X$ & TEM-1 & S91F, D95A & $\begin{array}{l}\text { S87N, } \\
\text { E91K }\end{array}$ & $\begin{array}{l}\text { G120K, } \\
\text { A121G }\end{array}$ & А39T & WT & WT & WT & All WT & - & + \\
\hline 2017570 & 2011 & 1407 (G1407) & - & 0.38 & 0.125 & 0.023 & 12 & 0.38 & 1 & 8 & 6 & L421P & XXXIV & - & S91F, D95G & $S 87 R$ & $\begin{array}{l}\text { G120K, } \\
\text { A121N }\end{array}$ & WT & $\begin{array}{c}\text { A } \\
\text { deletion }\end{array}$ & WT & WT & All WT & - & - \\
\hline 2004277 & 2011 & 8708 & - & 0.125 & $\leq 0.016$ & $\leq 0.002$ & $\leq 0.002$ & 0.25 & 0.5 & 8 & 4 & WT & $\|$ & - & WT & WT & WT & G45D & WT & WT & WT & All WT & - & - \\
\hline 1973517 & 2011 & 4232 & - & 0.19 & $\leq 0.016$ & 0.003 & $\leq 0.002$ & 0.19 & 16 & 8 & 6 & WT & $\|$ & - & WT & WT & A121S & G45D & WT & $W T^{d}$ & WT & All WT & - & + \\
\hline 1929711 & 2011 & 2992 (G2992) & - & 0.064 & $\leq 0.016$ & 0.003 & $\leq 0.002$ & 0.25 & 0.38 & 8 & 6 & WT & $\|$ & - & WT & WT & WT & $\begin{array}{l}\text { A39T, } \\
\text { R44H }\end{array}$ & WT & $W T^{d}$ & WT & All WT & - & - \\
\hline 1944251 & 2011 & 2992 (G2992) & - & 0.047 & $\leq 0.016$ & 0.003 & $\leq 0.002$ & 0.25 & 0.25 & 6 & 4 & WT & $\|$ & - & WT & WT & WT & $\begin{array}{l}\text { A39T, } \\
\text { R44H }\end{array}$ & WT & $W T^{d}$ & WT & All WT & - & - \\
\hline 1954615 & 2011 & 8707 & + & 12 & $\leq 0.016$ & 0.004 & 1.5 & 0.064 & 24 & 2 & 4 & L421P & XIX & TEM-1 & S91F, D95A & $S 87 R$ & A121S & А39T & WT & WT & WT & All WT & & + \\
\hline 1946253 & 2011 & 1407 (G1407) & & 0.38 & 0.125 & 0.032 & 32 & 0.75 & 1.5 & 8 & 6 & L421P & XXXIV & & S91F, D95G & $\mathrm{S} 87 \mathrm{R}$ & $\begin{array}{l}\text { G120K } \\
\text { A121N }\end{array}$ & WT & $\begin{array}{c}\text { A } \\
\text { deletion }\end{array}$ & WT & WT & All WT & & \\
\hline 2036196 & 2012 & 5528 & + & $>32$ & $\leq 0.016$ & 0.004 & 12 & 0.25 & 64 & 8 & 4 & WT & $\|$ & $\begin{array}{l}\text { TEM- } \\
135\end{array}$ & S91F, D95G & $\mathrm{D} 86 \mathrm{~N}$ & $\begin{array}{l}\text { G120K, } \\
\text { A121D }\end{array}$ & WT & WT & WT & WT & All WT & - & + \\
\hline 2086772 & 2012 & 8827 & + & 3 & $\leq 0.016$ & $\leq 0.002$ & 2 & 0.023 & 16 & 6 & 6 & L421P & $X I X$ & TEM-1 & S91F, D95A & $\begin{array}{l}\text { S87N, } \\
\text { E91K }\end{array}$ & $\begin{array}{l}\text { G120K, } \\
\text { A121D }\end{array}$ & Аз9Т & WT & WT & WT & All WT & - & + \\
\hline 2096513 & 2012 & 7616 & & 0.047 & $\leq 0.016$ & 0.002 & $\leq 0.002$ & 0.25 & 0.38 & 6 & 8 & WT & $\|$ & & WT & WT & WT & $\begin{array}{l}\text { A39T, } \\
\text { R44H }\end{array}$ & WT & $W T^{d}$ & WT & All WT & & - \\
\hline 2112655 & 2012 & 8826 & & 0.38 & 0.094 & 0.023 & 24 & 0.125 & 0.25 & 3 & 6 & L421P & XXXIV & & S91F, D95G & $S 87 R$ & $\begin{array}{l}\text { G120K, } \\
\text { A121N }\end{array}$ & WT & $\begin{array}{c}\text { A } \\
\text { deletion }\end{array}$ & WT & WT & All WT & & \\
\hline 2119347 & 2012 & 3378 & - & 0.38 & 0.094 & 0.032 & 16 & 0.5 & 1 & 8 & 12 & L421P & XXXIV & - & S91F, D95G & $S 87 R$ & $\begin{array}{l}\text { G120K, } \\
\text { A121N }\end{array}$ & WT & $\begin{array}{c}\text { A } \\
\text { deletion }\end{array}$ & WT & WT & All WT & - & - \\
\hline
\end{tabular}


Table 2 Phenotypic and molecular characteristics (clonality and drug resistance genes) of $26 \mathbf{N}$. gonorrhoeae isolates detected during the period $2010-2012$ in Switzerland (Continued)

\begin{tabular}{|c|c|c|c|c|c|c|c|c|c|c|c|c|c|c|c|c|c|c|c|c|c|c|c|c|}
\hline 2121127 & 2012 & 8825 & - & 0.125 & $\leq 0.016$ & 0.003 & 0.75 & $\leq 0.016$ & 0.25 & 2 & 1 & L421P & $\|$ & - & $\begin{array}{l}\text { S91F, A92S, } \\
\text { D95N }\end{array}$ & E91G & $\begin{array}{l}\text { G120K, } \\
\text { A121D }\end{array}$ & A39T & WT & $W T$ & WT & All WT & - & - \\
\hline 2129562 & 2012 & 437 (G225) & & 0.25 & 0.023 & 0.023 & 24 & 0.19 & 0.5 & 3 & 8 & L421P & v & & S91F, D95G & S87R & $\begin{array}{l}\text { G120K, } \\
\text { A121D }\end{array}$ & WT & $\begin{array}{c}\text { A } \\
\text { deletion }\end{array}$ & WT & WT & All WT & & \\
\hline 2131245 & 2012 & 8410 & + & 16 & 0.023 & 0.006 & 3 & 0.064 & 8 & 8 & 6 & WT & XXI-like & $\begin{array}{c}\text { TEM- } \\
135\end{array}$ & S91F, D95A & S87R & A121G & А39T & WT & WT & WT & All WT & & + \\
\hline 2132307 & 2012 & 3149 (G1407) & - & 0.38 & 0.094 & 0.023 & 32 & 0.38 & 1 & 8 & 8 & L421P & XXXIV & - & S91F, D95G & S87R & $\begin{array}{l}\text { G120K, } \\
\text { A121N }\end{array}$ & WT & $\begin{array}{c}\text { A } \\
\text { deletion }\end{array}$ & WT & WT & All WT & - & - \\
\hline
\end{tabular}

\section{Note. WT, wild-type; +, positive; -, negative.}

apenicillinase producers according to the cefinase disk test (Oxoid) and nitrocefin test.

${ }^{b}$ Abbreviations and MIC interpretation according to the EUCAST criteria [26]: penicillin (PEN; sensible, $\left.\mathrm{S} \leq 0.06 \mathrm{mg} / \mathrm{L}\right)$; ceftriaxone (CRO; $\left.\mathrm{S} \leq 0.125 \mathrm{mg} / \mathrm{L}\right) ;$ cefixime (CFX; $\left.\mathrm{S} \leq 0.125 \mathrm{mg} / \mathrm{L}\right) ;$ ciprofloxacin (CIP; $\mathrm{S} \leq 0.03 \mathrm{mg} / \mathrm{L}$ ); azithromycin (AZT; $S \leq 0.25 \mathrm{mg} / \mathrm{L}$ ); tetracycline (TET; $\mathrm{S} \leq 0.25 \mathrm{mg} / \mathrm{L}$ ); spectinomycin ( $\mathrm{SPE} ; \mathrm{S} \leq 64 \mathrm{mg} / \mathrm{L}$ ); gentamicin (GEN; criteria not available).

'The characteristics of the PBP2 patterns II, V, XII, and XIX were described by Whiley DM et al. [16], those of pattern XXXIV by Hess D et al. [28], and pattern IIg by Takahashi et al. [29]. Pattern XXI-like does not have $-574 \mathrm{~N}$ and $\mathrm{A} 575 \mathrm{~V}$ as in the XXI [16].

dThe $L 4$ of these $\mathrm{Ng}$ isolates possessed three substitutions (i.e., V125A, A147G, R157Q) that have no recognized impact on the macrolides resistance. 
hypothesize which countries were most responsible for this phenomenon. In fact, G1407 is currently the most frequently detected genogroup worldwide (e.g., 23\% of the isolates in Europe), whereas G225 and G2992 are second and third (e.g., 10\% and 8\% in Europe, respectively) [23]. For instance, ST1407 is first in rank in countries like Austria, Italy, the Netherlands, Portugal, Spain, Romania, Slovenia, United Kingdom, Japan and Canada; ST2992 is very frequent in Ireland and Norway; and ST225 is predominant in Malta and Denmark [19,21,24,38].

As also observed in this work, G1407 and G225 are constantly characterized by fully resistance to CIP and reduced susceptibility (at intermediate level) to PEN, AZT, and TET, whereas G2992 is usually pan-susceptible [3]. G1407 has also decreased susceptibility to CFX and, to a lesser extent, to CRO $[4,21,28]$. In this context, we note that most of the previously reported CFX or CRO treatment failures were due to $\mathrm{Ng}$ isolates of G1407 [4,11,12,39].

\section{Drug resistance genes}

Due to the number and complexity of the mechanisms [5], we decided to analyze only the main molecular traits of resistance possessed by the $\mathrm{Ng}$ isolates found during 2010-2012 (Table 2).

Isolates of G1407 were slightly resistant to PEN because of L421P in PBP1, overexpression of MtrCDE efflux by one A deletion in the promoter, and reduced permeability of PorB (substitutions G120K and A121N). However, they also showed augmented MICs to CFX and CRO due to the presence of the mosaic XXXIV $[4,8,21,28,36,38]$. This PBP2 variant may predispose the clone to become highly-resistant to CRO [11,12]. Similarly, G2992 and G225 tested intermediate to PEN, but were fully susceptible to cephalosporins because of the presence of PBP2 mosaics (i.e., II, V, XII, and XIX) that have little effects against CFX and CRO [16]. These commonly reported PBP2 mosaics were also present in the fully cephalosporinsusceptible $\mathrm{Ng}$ belonging to sporadic STs.

Non-hyperepidemic isolates were frequently TEM-1 producers but two of them expressed the TEM-135, a TEM-1 variant (substitution M182T) previously reported only in Japan, Thailand, and China $[8,40,41]$. TEM-135 is a plasmid-mediated enzyme that does not hydrolyze CFX and $\mathrm{CRO}$, but its emergence might represent an intermediate stage of the traditional TEM-1 penicillinase into an extended-spectrum $\beta$-lactamase (ESBL) that is able to confer high-level resistance to all $\beta$-lactams with the exception of carbapenems [4]. Since this was not a prospective clinical study, we are unable to provide information about the travel history of the two patients infected by TEM-135 producers.

None of the $\mathrm{Ng}$ tested possessed acquired genes (erm, mefA) or chromosomal mutations (23S rRNA, rplD, rplV) conferring high-level resistance to macrolides [5,7].
However, several isolates (including some of G1407 and G225) were non-susceptible to AZT (MICs of 0.38$0.75 \mathrm{mg} / \mathrm{L}$ ). This phenomenon may be due to a feeble overexpression of the MtrCDE efflux induced by the A deletion in the $m$ trR promoter $[5,9,42]$. Finally, almost all CIPresistant $\mathrm{Ng}$ possessed well-known substitutions in GyrA (amino acids 91 and 95) and ParC (amino acid 87). In particular, we highlight that the S91F replacement in GyrA was constantly observed, making it a good single target candidate for the molecular tests functional to categorize $\mathrm{Ng}$ as resistant or susceptible to quinolones [6]. The implementation of a rapid bedside molecular test for CIP resistance would allow treatment of infections due to susceptible isolates with this drug and could reduce the selective pressure on CRO in about $25 \%$ of gonorrhea in our country while still maintaining good clinical efficacy.

\section{Conclusions}

This is the first study describing clonality and molecular mechanisms of resistance of gonococcal isolates detected in Switzerland. In this survey, we also analyzed the changes in characteristics of $\mathrm{Ng}$ strains detected in the same geographic area and during the last 15 years. We note that studies focusing on these epidemiological temporal trends are still limited but extremely important to comprehend the spread and the evolution of antibiotic resistance in $\mathrm{Ng}[3,20,22,32]$.

Overall, our data clearly indicate that the antibiotic susceptibility of contemporary $\mathrm{Ng}$ isolates is dramatically decreasing, mainly due to the spread of international MDR clones that also show reduced susceptibility to the standard therapeutic options CRO and AZT [37]. These specific clones (e.g., ST1407 and its genogroups) are predisposed to become more resistant representing the last evolutionary step of the pathogen before the era of extensively and pandrug-resistant isolates [4]. In this context, we emphasize the urgent need of: $i$ ) rapid molecular tests able to provide adequate information to select the most appropriate direct antibiotic treatment [30]; ii) novel antimicrobial families against molecular targets not yet affected by resistance mechanisms [4]; iii) increasing numbers of cultures to study and monitor clonality and resistance mechanisms of gonococcus [4].

One limitation of the present study is that the survey was performed in a single institution, was not prospective, and included a relative small number of $\mathrm{Ng}$ isolates. However, we believe that our results may be representative for the whole country because distances in Switzerland are very short and our institution is located in the middle of the territory. In support of this speculation, we note that our phenotypic data are consistent with those recently provided by the larger analysis performed in Zurich [32].

To provide more robust and systematic data that are essential for controlling the rapidly increasing number of 
gonococcal STI, we strongly believe that an adequate national surveillance monitoring program - supported by the state public institutions - should be established rapidly and before our health care systems dramatically face the attack of untreatable gonococcal isolates $[4,17]$.

\section{Competing interests}

The authors declare that they have no competing interests.

\section{Authors' contributions}

AE: study design, results interpretation, and writing manuscript; YNG: molecular characterization, species identification, phenotypic tests; RT: molecular characterization; LH: molecular characterization and phenotypic tests; SS: species identification, phenotypic tests; AL: molecular characterization and reviewing manuscript; $\mathrm{CH}$ : reviewing manuscript; HF: study design and reviewing manuscript. All authors read and approved the final manuscript

\section{Acknowledgements}

We thank Selina Hutter and Salome N. Seiffert for helping with phenotypic tests and molecular analyses and Sara Droz for providing clinical isolates. This work was supported by internal funds of the Institute for Infectious Diseases and the Department of Infectious Diseases, Bern University Hospital. The study was also partially supported by a grant from the Bern University Hospital, Inselspital (CH, HF, and AE).

\section{Author details}

${ }^{1}$ Institute for Infectious Diseases, University of Bern, Bern, Switzerland. ${ }^{2}$ Department of Infectious Diseases, Bern University Hospital and University of Bern, Bern, Switzerland.

Received: 29 November 2013 Accepted: 20 February 2014 Published: 25 February 2014

\section{References}

1. World Health Organization (WHO): Department of Reproductive Health and Research. Global incidence and prevalence of selected curable sexually transmitted infections - 2008. Geneva, Switzerland: WHO; 2012.

2. World Health Organization (WHO): Department of Reproductive Health and Research. Global action plan to control the spread and impact of antimicrobial resistance in Neisseria gonorrhoeae. Geneva, Switzerland: WHO; 2012.

3. Ison CA, Alexander S: Antimicrobial resistance in Neisseria gonorrhoeae in the UK: surveillance and management. Expert Rev Anti Infect Ther 2011, 9(10):867-876

4. Unemo M, Nicholas RA: Emergence of multidrug-resistant, extensively drug-resistant and untreatable gonorrhea. Future Microbio/ 2012, 7(12):1401-1422.

5. Allen VG, Farrell DJ, Rebbapragada A, Tan J, Tijet N, Perusini SJ, Towns L, Lo S, Low DE, Melano RG: Molecular analysis of antimicrobial resistance mechanisms in Neisseria gonorrhoeae isolates from Ontario. Canada. Antimicrob Agents Chemother 2011, 55(2):703-712.

6. Zhao $L$, Zhao S: TaqMan real-time quantitative PCR assay for detection of fluoroquinolone-resistant Neisseria gonorrhoeae. Curr Microbiol 2012, 65(6):692-695

7. Chisholm SA, Dave J, Ison CA: High-level azithromycin resistance occurs in Neisseria gonorrhoeae as a result of a single point mutation in the $23 \mathrm{~S}$ rRNA genes. Antimicrob Agents Chemother 2010, 54(9):3812-3816.

8. Chen SC, Yin YP, Dai XQ, Yu RX, Han Y, Sun HH, Ohnishi M, Unemo M, Chen XS: Prevalence and molecular epidemiological typing of penicillinaseproducing Neisseria gonorrhoeae and their bla TEM-135 $_{\text {Gene Variants in }}$ Nanjing. China. Sex Transm Dis 2013, 40(11):872-876.

9. Warner DM, Shafer WM, Jerse AE: Clinically relevant mutations that cause derepression of the Neisseria gonorrhoeae MtrC-MtrD-MtrE Efflux pump system confer different levels of antimicrobial resistance and in vivo fitness. Mol Microbiol 2008, 70(2):462-478.

10. Shafer WM, Folster JP: Towards an understanding of chromosomally mediated penicillin resistance in Neisseria gonorrhoeae: evidence for a porin-efflux pump collaboration. J Bacterio/ 2006, 188(7):2297-2299.

11. Camara J, Serra J, Ayats J, Bastida T, Carnicer-Pont D, Andreu A, Ardanuy C: Molecular characterization of two high-level ceftriaxone-resistant
Neisseria gonorrhoeae isolates detected in Catalonia. Spain. J Antimicrob Chemother 2012, 67(8):1858-1860.

12. Unemo M, Golparian D, Nicholas R, Ohnishi M, Gallay A, Sednaoui P: High-level cefixime- and ceftriaxone-resistant Neisseria gonorrhoeae in France: novel penA mosaic allele in a successful international clone causes treatment failure. Antimicrob Agents Chemother 2012 56(3):1273-1280.

13. Chen CC, Yen MY, Wong WW, Li LH, Huang YL, Chen KW, Li SY: Tracing subsequent dissemination of a cluster of gonococcal infections caused by an ST1407-related clone harbouring mosaic penA alleles in Taiwan. J Antimicrob Chemother 2013, 68(7):1567-1571.

14. Ohnishi M, Saika T, Hoshina S, Iwasaku K, Nakayama S, Watanabe H, Kitawaki J: Ceftriaxone-resistant Neisseria gonorrhoeae, Japan. Emerg Infect Dis 2011, 17(1):148-149.

15. Tomberg J, Unemo M, Ohnishi M, Davies C, Nicholas RA: Identification of amino acids conferring high-level resistance to expanded-spectrum cephalosporins in the penA gene from Neisseria gonorrhoeae strain H041. Antimicrob Agents Chemother 2013, 57(7):3029-3036.

16. Whiley DM, Limnios EA, Ray S, Sloots TP, Tapsall JW: Diversity of penA alterations and subtypes in Neisseria gonorrhoeae strains from Sydney, Australia, that are less susceptible to ceftriaxone. Antimicrob Agents Chemother 2007, 51(9):3111-3116.

17. Ohnishi M, Golparian D, Shimuta K, Saika T, Hoshina S, Iwasaku K, Nakayama S, Kitawaki J, Unemo M: Is Neisseria gonorrhoeae initiating a future era of untreatable gonorrhea?: detailed characterization of the first strain with high-level resistance to ceftriaxone. Antimicrob Agents Chemother 2011, 55(7):3538-3545.

18. Gonococcal Isolate Surveillance Project (GISP): U.S. Department of Health \& Human Services - Public Health Service - Centers for Disease Control and Prevention (CDC). CDC; 2010.

19. European Centre for Diseases Prevention and Control (ECDC): Technical Report. Molecular typing of Neisseria gonorrhoeae. Results from a Pilot Study 2010-2011. Stockholm, 2012. ECDC; 2012

20. European Centre for Diseases Prevention and Control (ECDC): Surveillance Report. Gonococcal Antimicrobial Susceptibility Surveillance in Europe, 2011. Stockholm, 2013. ECDC; 2013.

21. Shimuta K, Unemo M, Nakayama S, Morita-Ishihara T, Dorin M, Kawahata T, Ohnishi M: Antimicrobial Resistance and Molecular Typing of Neisseria gonorrhoeae Isolates in Kyoto and Osaka, Japan, 2010 to 2012: Intensified Surveillance after Identification of the First Strain (H041) with High-Level Ceftriaxone Resistance. Antimicrob Agents Chemother 2013, 57(11):5225-5232.

22. Ison CA, Town K, Obi C, Chisholm S, Hughes G, Livermore DM, Lowndes CM: Decreased susceptibility to cephalosporins among gonococci: data from the Gonococcal Resistance to Antimicrobials Surveillance Programme (GRASP) in England and Wales, 2007-2011. Lancet Infect Dis 2013, 13(9):762-768.

23. Chisholm SA, Unemo M, Quaye N, Johansson E, Cole MJ, Ison CA, Van de Laar MJ: Molecular epidemiological typing within the European Gonococcal Antimicrobial Resistance Surveillance Programme reveals predominance of a multidrug-resistant clone. Euro Surveill 2013, 18(3).

24. Martin I, Sawatzky P, Liu G, Allen V, Lefebvre B, Hoang L, Lovgren M, Haldane D, Caeseele PV, Horsman G, et al: Antimicrobial susceptibilities and distribution of sequence types of Neisseria gonorrhoeae isolates in Canada: 2010. Can J Microbiol 2013, 59(10):671-678.

25. Mahon CR, Manuselis G: Textbook of Diagnostic Microbiology. 2nd edition. Philadelphia, Pennsylvania: W.B. Saunders Company; 2000.

26. EUCAST: European Committee on Antimicrobial Susceptibility Testing - Clinical breakpoints, Version 3.0, 2013; 2013.

27. Martin IM, Ison CA, Aanensen DM, Fenton KA, Spratt BG: Rapid sequence-based identification of gonococcal transmission clusters in a large metropolitan area. J Infect Dis 2004, 189(8):1497-1505.

28. Hess D, Wu A, Golparian D, Esmaili S, Pandori W, Sena E, Klausner JD, Barry $P$, Unemo M, Pandori M: Genome sequencing of a Neisseria gonorrhoeae isolate of a successful international clone with decreased susceptibility and resistance to extended-spectrum cephalosporins. Antimicrob Agents Chemother 2012, 56(11):5633-5641.

29. Takahashi S, Kurimura Y, Hashimoto J, Uehara T, Hiyama Y, Iwasawa A Nishimura M, Sunaoshi K, Takeda K, Suzuki N, et al: Antimicrobial susceptibility and penicillin-binding protein 1 and 2 mutations in 
Neisseria gonorrhoeae isolated from male urethritis in Sapporo, Japan. J Infect Chemother 2013, 19(1):50-56

30. Balashov S, Mordechai E, Adelson ME, Gygax SE: Multiplex bead suspension array for screening Neisseria gonorrhoeae antibiotic resistance genetic determinants in noncultured clinical samples. J Mo/ Diagn 2013, 15(1):116-129.

31. Le Lin B, Pastore R, Liassine N, Aramburu C, Sudre P: A new sexually transmitted infection (STI) in Geneva? Ciprofloxacin-resistant Neisseria gonorrhoeae, 2002-2005. Swiss Med Wkly 2008, 138(15-16):243-246.

32. Kovari H, de Melo Oliveira MD, Hauser P, Lauchli S, Meyer J, Weber R, Zbinden R: Decreased susceptibility of Neisseria gonorrhoeae isolates from Switzerland to Cefixime and Ceftriaxone: antimicrobial susceptibility data from 1990 and 2000 to 2012. BMC Infect Dis 2013, 13:603.

33. Ison CA, Hussey J, Sankar KN, Evans J, Alexander S: Gonorrhoea treatment failures to cefixime and azithromycin in England, 2010. Euro Surveill 2011, 16(14).

34. Unemo M, Golparian D, Syversen G, Vestrheim DF, Moi H: Two cases of verified clinical failures using internationally recommended first-line cefixime for gonorrhoea treatment, Norway, 2010. Euro Surveill 2010, 15(47).

35. Unemo M, Golparian D, Hestner A: Ceftriaxone treatment failure of pharyngeal gonorrhoea verified by international recommendations, Sweden, July 2010. Euro Surveill 2011, 16(6).

36. Lewis DA, Sriruttan C, Muller EE, Golparian D, Gumede L, Fick D, de Wet J, Maseko V, Coetzee J, Unemo M: Phenotypic and genetic characterization of the first two cases of extended-spectrum-cephalosporin-resistant Neisseria gonorrhoeae infection in South Africa and association with cefixime treatment failure. J Antimicrob Chemother 2013, 68(6):1267-1270.

37. Unemo M: The 2012 European guideline on the diagnosis and treatment of gonorrhoea in adults recommends dual antimicrobial therapy. Euro Surveill 2012, 17(47)

38. Heymans R, Bruisten SM, Golparian D, Unemo M, de Vries HJ, van Dam AP: Clonally related Neisseria gonorrhoeae isolates with decreased susceptibility to the extended-spectrum cephalosporin cefotaxime in Amsterdam, the Netherlands. Antimicrob Agents Chemother 2012, 56(3):1516-1522

39. Allen VG, Mitterni L, Seah C, Rebbapragada A, Martin IE, Lee C, Siebert H, Towns L, Melano RG, Low DE: Neisseria gonorrhoeae treatment failure and susceptibility to cefixime in Toronto. Canada. Jama 2013, 309(2):163-170.

40. Nakayama S, Tribuddharat C, Prombhul S, Shimuta K, Srifuengfung S, Unemo M, Ohnishi M: Molecular analyses of TEM genes and their corresponding penicillinase-producing Neisseria gonorrhoeae isolates in Bangkok. Thailand. Antimicrob Agents Chemother 2012, 56(2):916-920.

41. Ohnishi $M$, Ono E, Shimuta $K$, Watanabe $H$, Okamura $N$ : Identification of TEM-135 $\beta$-lactamase in penicillinase-producing Neisseria gonorrhoeae strains in Japan. Antimicrob Agents Chemother 2010, 54(7):3021-3023.

42. Ng LK, Martin I, Liu G, Bryden L: Mutation in 23S rRNA associated with macrolide resistance in Neisseria gonorrhoeae. Antimicrob Agents Chemother 2002, 46(9):3020-3025.

doi:10.1186/1471-2334-14-106

Cite this article as: Endimiani et al:: Characterization of Neisseria gonorrhoeae isolates detected in Switzerland (1998-2012): emergence of multidrug-resistant clones less susceptible to cephalosporins. BMC Infectious Diseases 2014 14:106.

\section{Submit your next manuscript to BioMed Central and take full advantage of:}

- Convenient online submission

- Thorough peer review

- No space constraints or color figure charges

- Immediate publication on acceptance

- Inclusion in PubMed, CAS, Scopus and Google Scholar

- Research which is freely available for redistribution

Submit your manuscript at www.biomedcentral.com/submit
C Biomed Central 